\title{
Primary cilia elongation in response to interleukin-1 mediates the inflammatory response
}

\author{
A. K. T. Wann $\cdot$ M. M. Knight
}

Received: 7 October 2011 / Revised: 20 March 2012 / Accepted: 22 March 2012 / Published online: 6 April 2012

(C) The Author(s) 2012. This article is published with open access at Springerlink.com

\begin{abstract}
Primary cilia are singular, cytoskeletal organelles present in the majority of mammalian cell types where they function as coordinating centres for mechanotransduction, Wnt and hedgehog signalling. The length of the primary cilium is proposed to modulate cilia function, governed in part by the activity of intraflagellar transport (IFT). In articular cartilage, primary cilia length is increased and hedgehog signaling activated in osteoarthritis (OA). Here, we examine primary cilia length with exposure to the quintessential inflammatory cytokine interleukin-1 (IL-1), which is up-regulated in OA. We then test the hypothesis that the cilium is involved in mediating the downstream inflammatory response. Primary chondrocytes treated with IL-1 exhibited a $50 \%$ increase in cilia length after $3 \mathrm{~h}$ exposure. IL-1-induced cilia elongation was also observed in human fibroblasts. In chondrocytes, this elongation occurred via a protein kinase A (PKA)dependent mechanism. G-protein coupled adenylate cyclase also regulated the length of chondrocyte primary cilia but not downstream of IL-1. Chondrocytes treated with IL-1 exhibit a characteristic increase in the release of the inflammatory chemokines, nitric oxide and prostaglandin E2. However, in cells with a mutation in IFT88 whereby the cilia structure is lost, this response to IL-1 was significantly attenuated and, in the case of nitric oxide, completely abolished. Inhibition of IL-1-induced cilia elongation by PKA inhibition also attenuated the chemokine response. These results suggest that cilia assembly
\end{abstract}

\footnotetext{
A. K. T. Wann $(\varangle) \cdot$ M. M. Knight

Biomedical Engineering, 2nd Floor Cell and Tissue Laboratories, School of Engineering and Materials Science, Queen Mary, University of London, Mile End Road, London E1 4NS, UK

e-mail: a.wann@qmul.ac.uk
}

regulates the response to inflammatory cytokines. Therefore, the cilia proteome may provide a novel therapeutic target for the treatment of inflammatory pathologies, including OA.

Keywords Primary cilia - Inflammation · Cytokine . Protein kinase A - Chondrocyte

\section{Introduction}

Primary cilia are single finger-like projections that extend several microns into the extracellular environment and are expressed by the majority of eukaryotic cells. Despite their discovery more than a century ago, only in the last few decades has evidence been gathered to highlight the role that this tubulin-based structure plays in many facets of cell biology, including differentiation and vertebrate development [1, 2], cell cycle control [3], cancer signaling [4], sensory function and migration [5], and mechanotransduction [6-9]. The primary cilia axonome is extended from the basal body upon entry to G0, and its genesis, maintenance, and function rely upon intraflagellar transport (IFT) [10]. The large number of ciliopathies have served both to emphasize the physiological importance of the primary cilium and to provide models to better understand their function [11]. Many of these pathologies are associated with alterations in cilia length [12], adding support to the concept of a cilia structure-function relationship [13-15].

Axonomal length control has been extensively studied in model systems such as Chlamydomonas [16-18] and C. elegans [17, 19] since 1969. Mechanisms acting to regulate flagellar length include $\mathrm{Ca}^{2+}$ concentration [20] and protein phosphorylation [21]. A correlation between cilia length and IFT particle size has also been observed 
[18]. Study of ciliary length in mammalian cells has indicated many factors regulating axonomal length. These include reduced intracellular calcium and increased cyclic AMP (cAMP) acting to elongate cilia, through a PKAdependent increase in anterograde (towards the tip) IFT [14]. Molecular approaches have identified the involvement in cilia length control of molecules engaged in the organization of the actin cytoskeleton and in soluble tubulin levels [22, 23]. Most recently, work in vascular endothelium has elucidated roles for protein kinase $\mathrm{C}$ (PKC) and mitogen-activated (MAP) protein kinases [15]. Cilia elongation receives ever-increasing interest, as reviewed recently [24].

A large contingent of diseases including arthritis, arthrosclerosis, and cancer involve inflammation. In articular cartilage, where primary cilia protrude into the extracellular matrix [25], the degenerative condition of OA is associated with increases in cilia length and prevalence [26], and the increased expression of hedgehog signaling genes [27]. More broadly, studies in kidney epithelium suggest that cilia length changes post-injury are important in the process of renal repair [28]. Cytokines are involved in a huge range of physiological and pathological processes [29]. In inflammatory pathologies, the quintessentially proinflammatory cytokine Interleukin- $1 \beta$ (IL-1 $\beta$ ) and its receptors are up-regulated as part of the broad spectrum of inflammatory mediators activated in many cell types. As such, we hypothesized that IL-1 exposure increases cilia length and that the cilium is involved in inflammatory signaling. We show that primary cilia length is increased by IL-1 and that cilia elongation drives the downstream inflammatory response in the form of chemokine release. This suggests, for the first time, that primary cilia and IFT play an important role in inflammation. These studies, therefore, open the door to a host of new therapeutic targets for a wide variety of inflammatory pathologies.

\section{Materials and methods}

\section{Cell culture}

Bovine forefeet from 18-month-old steers were obtained fresh from slaughter from a local abattoir and primary chondrocytes isolated by enzymatic digestion as previously described [30]. Cells were cultured in Dulbecco's Modified Eagles Medium (DMEM; Sigma-Aldrich, Poole, UK) supplemented with $10 \%$ (v/v) fetal calf serum (FCS), $1.6 \mathrm{mM}$ L-glutamine, $81 \mu \mathrm{mL}^{-1}$ penicillin, $80 \mu \mathrm{g} \mathrm{mL}^{-1}$ streptomycin, $16 \mathrm{mM}$ HEPES buffer, and $0.68 \mathrm{mM}$ 1-ascorbic acid (all Sigma-Aldrich). Cells were seeded onto FCS-coated glass coverslips at $6 \times 10^{4}$ cells $\mathrm{cm}^{2}$ and cultured for 5 days to attach.
$\operatorname{Tg} 737^{\text {ORPK }}$ (heterozygous) mutant mice lines were generated as previously described [31]. Mice were maintained on a mixed genetic background according to approved protocols at the Medical University of South Carolina. Heterozygous $O R P K$ mice were bred with heterozygous Immortomouse mice $(H-2 \mathrm{~Kb}$-tsA58) which harbor a temperature sensitive SV40 large $\mathrm{T}$ antigen transgene under the control of an interferon- $\gamma$-inducible $H-2 \mathrm{~Kb}$ promoter $(\mathrm{H}-2 \mathrm{~Kb}$-tsA58) to produce orpk/Immortomouse compound heterozygous mice [32]. Heterozygous ORPK females were bred with heterozygous/Immortomouse orpk males. Chondrocytes were isolated from the sternum of 4-day-old mice by digestion with collagenase type II $\left(2 \mathrm{mg} \mathrm{mL}^{-1}\right)$ dispersed in DMEM at $37{ }^{\circ} \mathrm{C}$ for $4 \mathrm{~h}$. All mice were genotyped by PCR from tail biopsy DNA. Western blot analysis was conducted to confirm the expression of SV40 large T antigen protein in chondrocytes in the presence of IFN- $\gamma$ at $33{ }^{\circ} \mathrm{C}$. Cells were cultured in DMEM supplemented with $10 \%$ FCS, $88 \mathrm{U} \mathrm{mL}^{-1}$ penicillin, $90 \mu \mathrm{g} \mathrm{mL}^{-1}$ streptomycin, $10 \mathrm{ng} \mathrm{mL}{ }^{-1} \mathrm{INF}-\gamma$, and $2.5 \mathrm{mM}$ L-glutamine. Immortalized cells were grown to $90 \%$ confluence in $5 \% \mathrm{CO}_{2} / 33{ }^{\circ} \mathrm{C}$ plus $10 \mathrm{nM}$ IFN $-\gamma$, then cultured in non-permissive conditions at $37^{\circ} \mathrm{C}$ $(-\mathrm{IFN}-\gamma)$ for 4 days before seeding onto glass FCS-coated coverslips at $6 \times 10^{4}$ cells $\mathrm{cm}^{2}$. Proliferation rates (as assessed by ki-67 staining) were very low during the 48 -h treatment period. This was associated with no statistically significant variation in cell number between treatments as indicated by a fluorescence DNA quantification assay using Hoescht 33258.

NIH3T3 cells were cultured in DMEM supplemented with $10 \%$ FCS, $88 \mathrm{U} \mathrm{mL}^{-1}$ penicillin, $90 \mu \mathrm{g} \mathrm{mL}^{-1}$ streptomycin, and $2.5 \mathrm{mM}$ L-glutamine. Cultures were serum starved for $12 \mathrm{~h}$ to encourage cilia expression and near-abolish proliferation prior to exposure to IL-1.

Interleukin treatment

IL-1 $\beta$ was obtained from Peprotech (London, UK), and reconstituted to $1 \mathrm{mg} \mathrm{mL}^{-1}$ from solid lyophilized sterile powder in distilled water. This stock was then added to serum-supplemented DMEM and frozen in aliquots at $10 \mu \mathrm{g} \mathrm{mL}^{-1}$. When required, aliquots of $\mathrm{IL}-1 \beta$ were thawed and diluted to $10 \mathrm{ng} \mathrm{ml}^{-1}$ in media.

Immunofluorescent staining

Following fixation in $3.7 \%$ paraformaldehyde at $37{ }^{\circ} \mathrm{C}$ for 8 min, coverslip cultures were permeabilized in $0.5 \%$ triton and blocked with $5 \%$ goat serum. Coverslips were incubated overnight at $4{ }^{\circ} \mathrm{C}$ with anti-acetylated $\alpha$-tubulin primary antibody (clone 6-11B-1, 1:2,000; Sigma-Aldrich), washed, and incubated for $2 \mathrm{~h}$ at $25{ }^{\circ} \mathrm{C}$ with Alexa 488 
anti-mouse conjugate (Invitrogen, UK) before mounting with a DAPI counterstain (Invitrogen). Ki-67 staining was conducted in identical fashion using mouse anti-ki-67 (Sigma-Aldrich) and an Alexa 594 anti-mouse conjugate (Invitrogen).

Imaging and cilia length measurements

A Leica SP2 confocal microscope was used to create maximum projections of confocal $z$-stacks (Fig. 1a) from which cilia length was measured using image $\mathbf{J}$ software. At least three different mounted preparations were used to capture five fields of cells at $\times 63$ magnification giving data for $>100$ cilia per subgroup. Confocal $z$ maximum projections were also used to assess cilia prevalence and ki-67 nuclear staining.

\section{Pharmacological agonists/antagonists}

All experiments to investigate mechanism were conducted over $24 \mathrm{~h}$ with $10 \mathrm{ng} \mathrm{mL} \mathrm{mL}^{-1} \mathrm{IL}-1 \beta$. All reagents from Merck Chemicals, UK. Table 1 shows the concentrations and mode of action of the various agonists and antagonists used throughout this study.

a
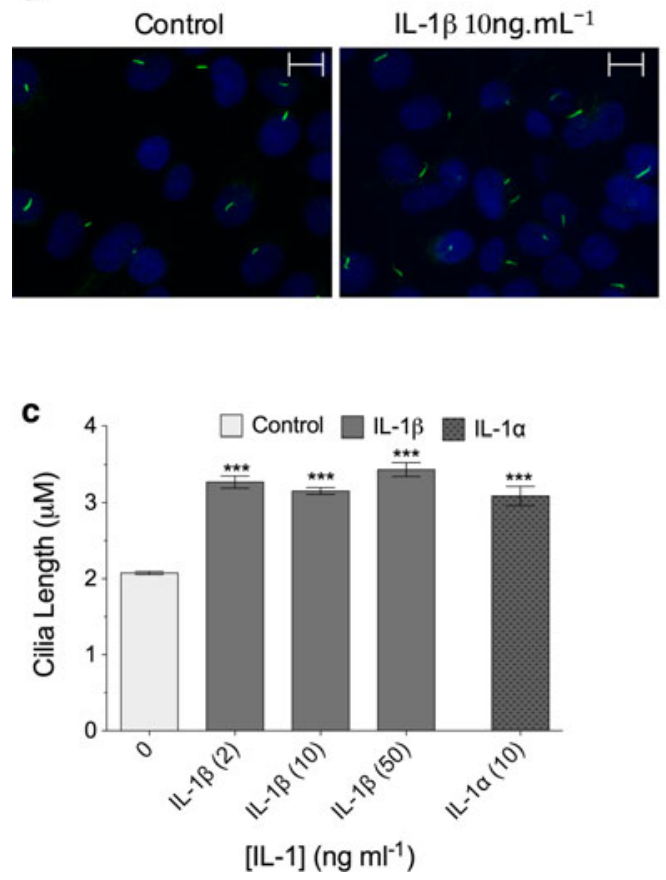

Fig. 1 IL-1 increases primary cilia length in chondrocytes. a Chondrocyte primary cilia (green, anti-acetylated- $\alpha$-tubulin, blue DAPI nuclei). Scale bar $10 \mu \mathrm{m}$. b Frequency histogram of chondrocyte cilia length showing elongation of cilia associated with IL- $1 \beta$ treatment $\left(10 \mathrm{ng} \mathrm{mL}^{-1}, 24 \mathrm{~h}\right)$. Insert shows that negligible cells were in a proliferative state as indicated by nuclear ki-67 expression. $\mathbf{c}$ IL-1 $\beta$ at
$\mathrm{PGE}_{2}$ and NO quantification

A commercially available quantitative immunoassay (R\&D Systems, UK) was used to quantify media $\mathrm{PGE}_{2}$ concentrations immediately following 48-h IL-1 $\beta$ treatment. Samples were diluted threefold before addition to a goatanti-mouse microplate. Addition of a horseradish peroxidase-labeled $\mathrm{PGE}_{2}$ ensured $\mathrm{PGE}_{2}$ in the sample competed for binding with a monoclonal antibody, which was quantified by measuring absorbance at $450 \mathrm{~nm}$ following washing and addition of a substrate solution. Results were corrected for non-specific binding and read from a $\mathrm{PGE}_{2}$ standard curve fitted in GraphPad Prism 5. Nitrite, the stable product of NO degradation, content was quantified in the media without dilution, after an identical 48-h experiment, by spectrometric Greiss reagent assay [33], measuring absorbance at $544 \mathrm{~nm}$. The same methodologies were used for murine cells investigating the role of IFT88 and for bovine cells investigating the role of PKA.

\section{Statistics}

Data are presented using mean \pm SEM. Due to the skewed nature of the data for cilia length, non-parametric statistical analysis was used in the form of Mann-Whitney $U$ tests.
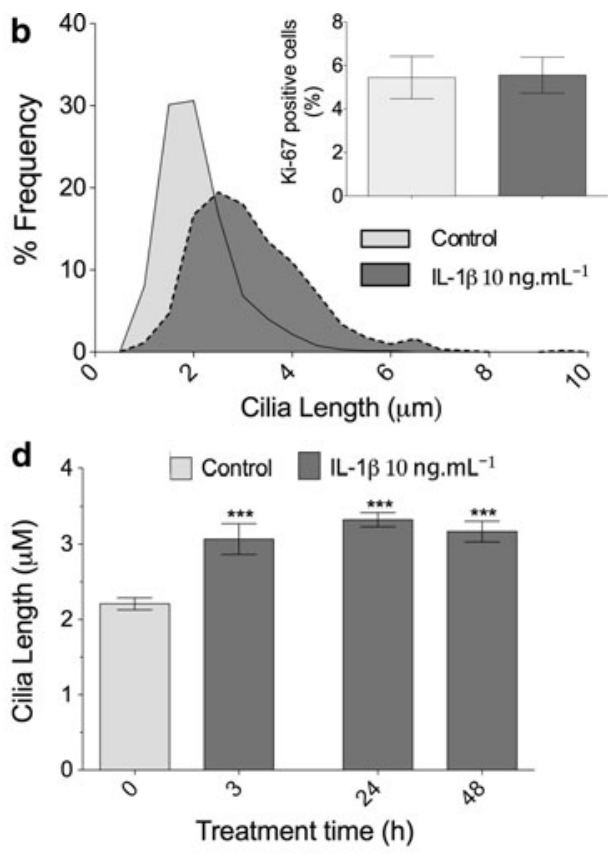

2-50 ng mL ${ }^{-1}$ induced statistically significant increases in cilia length as did IL- $1 \alpha$ at $10 \mathrm{ng} \mathrm{mL}^{-1}$, but no statistically significant differences were seen between the different concentration or type of IL-1 used. d The influence of IL-1 was observed at $3 \mathrm{~h}$ and the effect maintained throughout a 48 -h treatment period. Statistically significant differences are indicated relative to untreated control 
Table 1 The concentrations, modes of action and summary effects of pharmacological agonists/antagonists

\begin{tabular}{llllll}
\hline Drug name & Abbreviation & Concentration & Mode of action & $\begin{array}{l}\text { Effect on cilia } \\
\text { length }\end{array}$ & $\begin{array}{l}\text { Effect on IL-1 } \\
\text { elongation }\end{array}$ \\
\hline PKI (14-22 amide inhibitor) & PKI & $10 \mu \mathrm{M}$ & Peptide PKA inhibitor & No effect & Complete inhibition \\
H89 & H89 & $0.5 \mu \mathrm{M}$ & ATP-site inhibitor of PKA & No effect & Complete inhibition \\
Bisindolylmaleimide I & BIM1 & $0.5 \mu \mathrm{M}$ & ATP-site inhibitor of PKC & No effect & Partial inhibition \\
PD98059 & PD98059 & $10 \mu \mathrm{M}$ & MEK-ERK inhibitor & No effect & Complete inhibition \\
8-Bromo-adenosine & 8-Br & $10-100 \mu \mathrm{M}$ & cAMP analogue-Activates PKA & Increase & Supplementary \\
2'-5' dideoxyadenosine $^{\text {a }}$ & DOA & $10 \mu \mathrm{M}$ & p-site inhibitor of adenylate cyclase & Increase & Supplementary \\
Pertussis toxin $^{\text {b }}$ & PT & $1 \mu \mathrm{g} \mathrm{mL} \mathrm{L}^{-1}$ & ADP-Ribosylation of G $\alpha$ i subunit & Increase & No net effect \\
\hline
\end{tabular}

${ }^{a}$ Dideoxyadenosine was additionally re-dosed after $12 \mathrm{~h}$. Vehicles at equal volume were added to untreated controls. A summary of effects both on baseline and IL-1-treated ciliary length has been included

b Pertussis toxin was added to cultures $6 \mathrm{~h}$ before IL-1 treatment. All other agents were added at the same time-points and for $24 \mathrm{~h}$

Unpaired Student's $t$ tests were used for analysis of nitrite and $\mathrm{PGE}_{2}$ release. For all statistics, a two-tailed approach was used with $p<0.05$ indicating a statistically significant difference. In the figures, ${ }^{*} p<0.05,{ }^{* *} p<0.01,{ }^{* * *} p<0.0001$.

\section{Results}

\section{IL-1 exposure increases primary cilia length}

Freshly isolated chondrocytes expressed primary cilia with a mean length of $\sim 2 \mu \mathrm{m}$ in monolayer cultures, with $>75 \%$ of cilia between 1 and $3 \mu \mathrm{m}$ long. Exposure for $24 \mathrm{~h}$ to $\mathrm{IL}-1 \beta$, at the commonly used experimental concentration of $10 \mathrm{ng} \mathrm{mL}^{-1}$, statistically significantly increased the length of cilia in primary chondrocytes ( $p<0.0001, n=9$ independent experiments; $>600$ cilia; Fig. 1a). Most strikingly, IL-1 increased the number of cells with cilia $>3 \mu \mathrm{m}$ long (Fig. 1b). To assess the cell cycle status of the cells, the proliferative marker ki-67 was utilized to label cells outside of G0 phase. This indicated that only a very small proportion $(<6 \%)$ of the freshly isolated cells, were outside of quiescence and, as such, effects on cilia length were not due to alterations in proliferation (Fig. 1b, insert). The approximate $50 \%$ increase in cilia length was also observed using IL1- $\beta$ at both a lower, $2 \mathrm{ng} \mathrm{mL}^{-1}$, and a higher, $50 \mathrm{ng} \mathrm{mL}^{-1}$, concentration and also when IL- $1 \alpha$ was used at $10 \mathrm{ng} \mathrm{mL}^{-1}$ (Fig. 1c). A similar statistically significant $50 \%$ elongation was found after 3, 24, and $48 \mathrm{~h}$ exposure to IL-1 $\beta$ (Fig. 1d). No statistically significant differences were seen between concentrations, between the two IL-1 types or between time-points. For all comparisons, $p<0.0001$, $n=3$ independent experiments; $>100$ cilia. Cilia prevalence varied between preparations (40-60\%); however, no statistically significant differences were observed between treatment groups.
IL-1 induction of cilia elongation also occurs in fibroblasts

Most eukaryotic cells express primary cilia. The cilium conducts a wide variety of roles in different cell types including epithelia [7], bone [6, 34], endothelium [15], and fibroblasts [5]. A large amount of primary cilia experiments have been conducted in the fibroblast cell line NIH3T3 [35]. In order to check if the IL-1 phenomenon was exhibited by cells other than bovine chondrocytes, we investigated IL-1 stimulation in this human fibroblast cell line. With serum-starvation and high seeding density, the cells exhibited a highly quiescent profile with $80 \%$ cilia expression (Fig. 2a). In response to $10 \mathrm{ng} \mathrm{mL} \mathrm{IL-1,} \mathrm{mean}$ cilia length in NIH3T3 fibroblasts was increased by $27 \%$ from a mean value of 2.7-3.4, the difference being statistically significant after $24 \mathrm{~h}$ exposure $(p<0.0001, n=3$ independent experiments; $>170$ cilia; Fig. $2 b$ ). This represented a more subtle, but nevertheless convincing, shift towards longer cilia (Fig. 2c) than observed in primary chondrocytes (Fig. 1b).

\section{IL-1 induced cilia elongation occurs via protein kinases including PKA}

Previous studies in other cell types have shown the influence of adenylate cyclase, cAMP, cAMP-activated protein kinase A (PKA), and PKC and MAP kinases on primary cilia length $[14,15]$. First, a role for PKA in IL-1 stimulated elongation was tested using PKA inhibitors PKI and H89 (Fig. 3a). Both drugs prevented cilia elongation associated with $24 \mathrm{~h}$ exposure to IL-1 $\beta\left(10 \mathrm{ng} \cdot \mathrm{mL}^{-1}\right)$ such that increases in length with IL- $1 \beta$ treatment were not statistically significant $(n=3$ independent experiments; each $>100$ cilia). Neither inhibitor elicited an effect on cilia length when used without IL-1 (Fig. 3a). 
Fig. 2 IL-1 increases primary cilia length in human fibroblasts. a, b

Immunofluorescent staining of cilia in human fibroblasts (green, anti-acetylated- $\alpha$ tubulin, blue DAPI nuclei). Scale bar $10 \mu \mathrm{m}$. b, c IL-1 $\beta$ $\left(10 \mathrm{ng} \mathrm{mL}^{-1}, 24 \mathrm{~h}\right)$ induced a statistically significant increase in primary cilia length in human fibroblasts. d Frequency histogram of fibroblast cilia length a
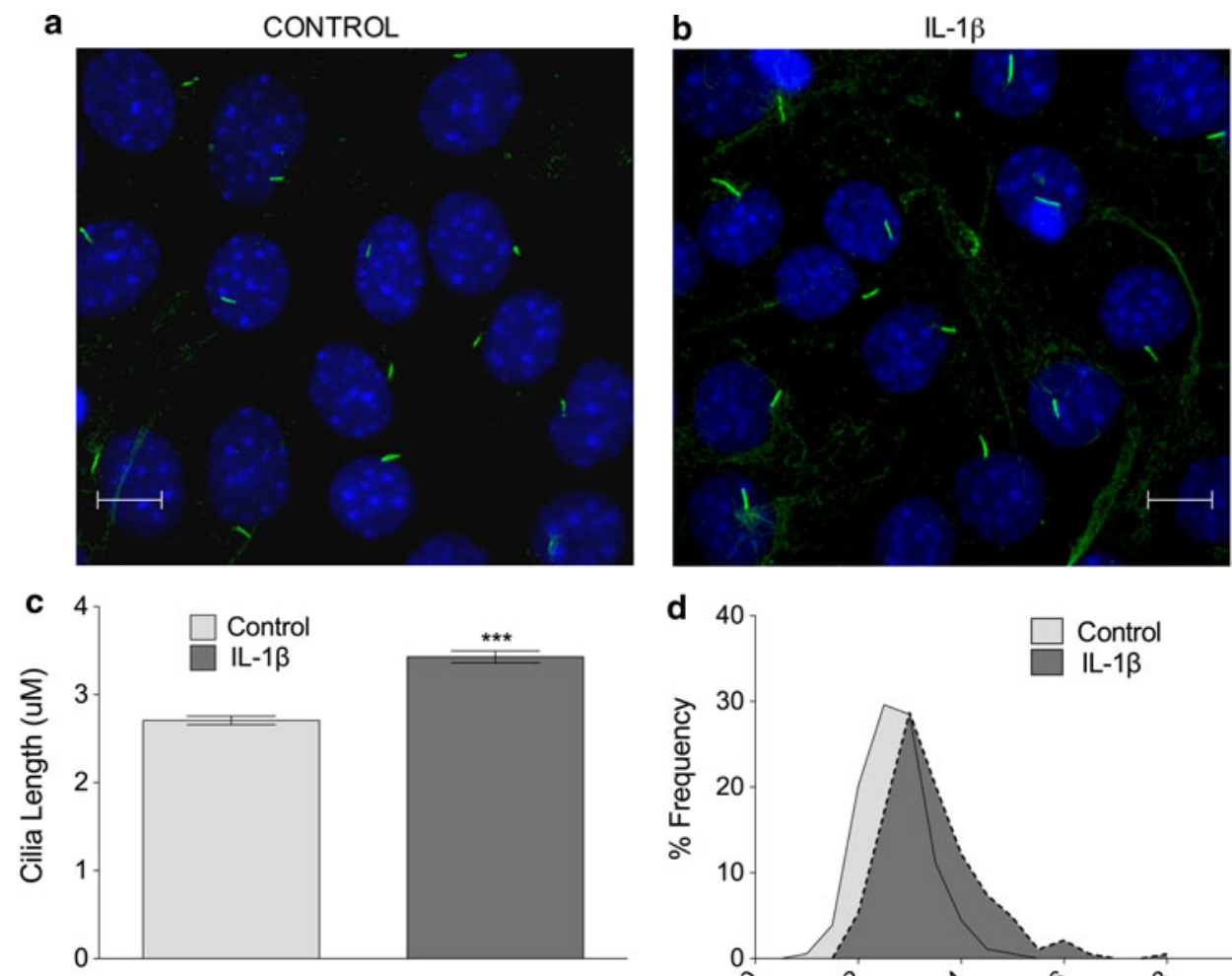

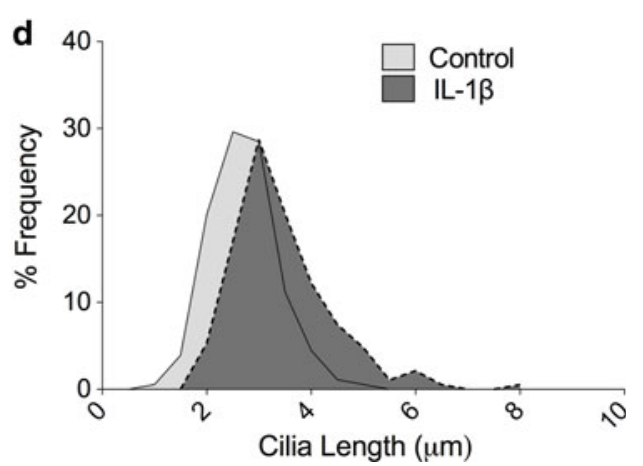

Second, using the same pharmacological inhibitors as previous studies investigating PKC and MEK-ERK, bisindolylmaleimide I or BIM1 $(0.5 \mu \mathrm{M})$ and PD98059 $(10 \mu \mathrm{M})$, respectively, we investigated the importance of these kinases in IL- $1 \beta$-stimulated cilia elongation. Whilst neither inhibitor influenced control of cilia length without IL-1, both statistically significantly reduced $(p<0.0001)$ the response to IL-1 (Fig. 3b). BIM1 had a partially inhibitory effect, but in the case of PD98059, the IL- $1 \beta$ induced cilia elongation was completely abolished. For all experiments, $n=3$ independent experiments; $>100$ cilia.

cAMP level also regulates chondrocyte cilia length via PKA but not in response to IL-1

In light of the PKA results, we next investigated the effect of the cAMP analogue 8-Br-cAMP on cilia length in chondrocytes. Addition of this cAMP analogue at $10 \mu \mathrm{M}$ produced a statistically significant increase in cilia length after $24 \mathrm{~h}$ treatment (31\%, $p<0.0001$; Fig. 4a). 8-BrcAMP elicited this effect with increasing potency from 10 to $100 \mu \mathrm{M}$ ( $p<0.0001$, Kruskal-Wallis test, $n=3$ independent experiments; $>100$ cilia). With $100 \mu \mathrm{M}$ treatment, cilia length increased within 3 h (a $39 \%$ increase in mean, $p<0.0001$ ), but most striking results were seen at $24 \mathrm{~h}$ (a $75 \%$ increase in mean, $p<0.0001$, time-course data not shown). The effect of $10 \mu \mathrm{M} 8$-BR-cAMP was abolished by addition of either the PKA inhibitor 14-22 amide fragment, PKI $(10 \mu \mathrm{M})$ or PKA inhibitor H89 $(0.5 \mu \mathrm{M})$ such that cilia length was not statistically significantly from control (Fig. 4a). As such, cAMP-PKA regulation of cilia length is shown to be active in chondrocytes.

Given the ability of cAMP to elicit cilia lengthening, we next hypothesized that IL-1 may be eliciting its influence via $\mathrm{G}$ protein activation of adenylate cyclase and resulting conversion of ATP to cAMP. To investigate the roles of $G$ proteins and adenylate cyclase (AC), cultures were treated with the G-protein inhibitor, pertussis toxin (PT) and the p-site adenylate cyclase antagonist, $2^{\prime}-5^{\prime}$ deoxyadenosine (DOA). Pertussis toxin had a stimulatory influence on cilia length with a $57 \%$ increase in mean length $(p<0.0001)$. No additional effect was seen when IL-1 was added in conjunction with pertussis toxin (Fig. 4b). Inhibition of adenylate cyclase, without IL- $1 \beta$, increased mean cilia length by $83 \%(p<0.0001)$. However, the effects of IL- $1 \beta$ and DOA were additive, such that, when cells were exposed to both, there was a $137 \%$ increase in mean cilia length compared to the untreated control without IL-1 $\beta$ $(p<0.0001$; Fig. 4c). Thus, DOA and PT had no negative effect on the IL-1 $\beta$-induced increase in cilia length which remained statistically significant $(p<0.0001)$. An inhibition of adenylate cyclase has previously been proposed as a mechanism of ciliary elongation [35], therefore, to establish if cAMP may be able to recover IL-1-induced changes, cells were treated with both IL-1 and 8-BR-cAMP (Fig. 4d). This produced a statistically significant increase 

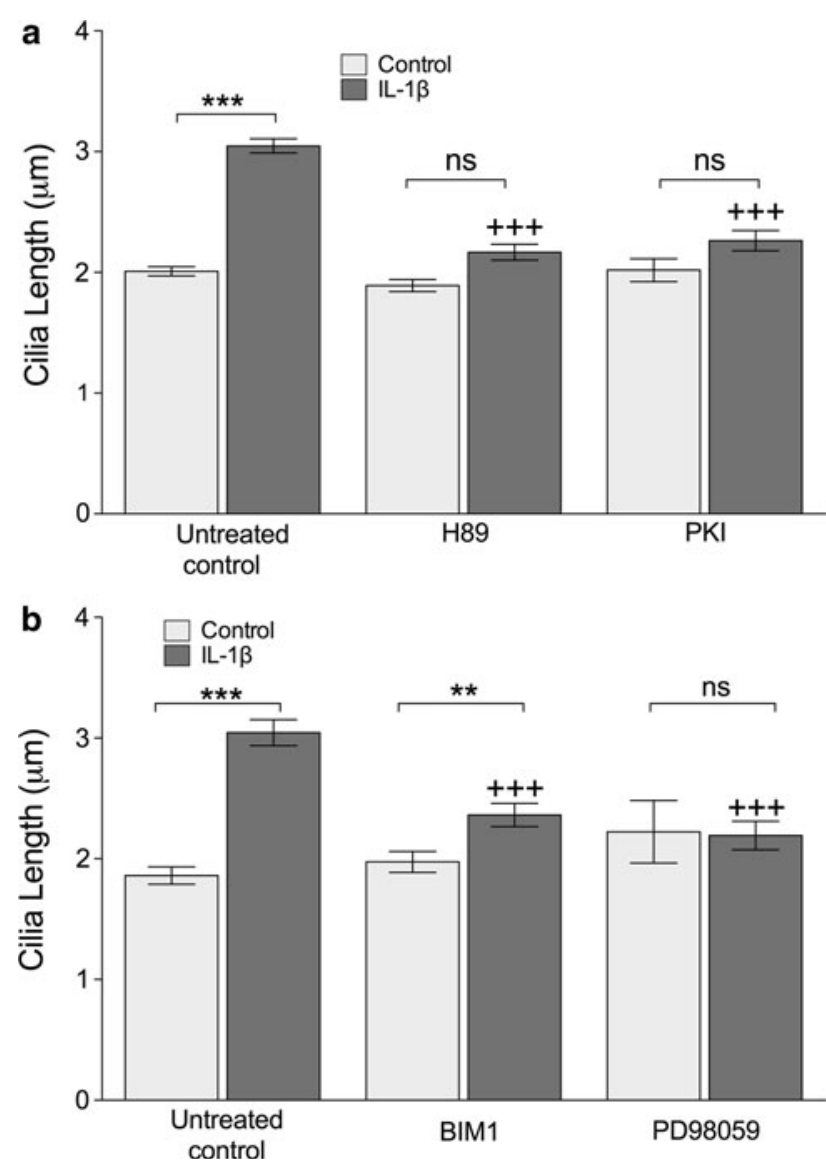

Fig. 3 IL-1 induced cilia elongation occurs via kinase activity including PKA a IL-1 stimulated elongation was abolished ( $+++p<0.0001$ with respect to $\mathrm{IL}-1$ only) by treatment with PKA antagonists H89 and PKI. b Inhibition of PKC by bisindolylmaleimide I (BIM1) resulted in the substantial inhibition of IL-1 induced elongation $(+++p<0.0001$ with respect to IL-1 only). MEK-ERK inhibition by PD98059 abolished IL-1-induced elongation. Neither drug had an effect on cilia length in untreated cells

in cilia length compared to IL- $1 \beta$ alone $(p<0.01)$. For all experiments, $n=3$ independent experiments; $>100$ cilia. There is, therefore, no evidence for any link between AC-cAMP signaling and IL-1-induced cilia elongation.

IFT88 is required for inflammatory responses to interleukin-1

To assess the downstream functionality of cilia elongation in an inflammatory context, we employed a genetic approach to knockout IFT88 whilst assessing IL-1 stimulated $\mathrm{PGE}_{2}$ and nitrite release (indicative of nitric oxide release), classic inflammatory results of cytokine exposure in many cell types. When cultured in identical conditions to bovine primary chondrocytes wild-type (WT) murine cells exhibited approximately $40 \%$ ciliation (Fig. 5a), whilst mutated $(O R P K)$ cells exhibited no cilia (Fig. 5b). IL-1 $\beta$ treatment $(48 \mathrm{~h})$ elicited the expected large (32.9-fold) and

statistically significant $(p>0.0001$, unpaired Student's $t$ test, $n=7$ preparations) increase in $\mathrm{PGE}_{2}$ in the culture medium (Fig. 5c). However, when ORPK cells were exposed to an identical IL-1 $\beta$ treatment, the increase in $\mathrm{PGE}_{2}$ was muted by comparison, only a 13 -fold increase, albeit still statistically significant $(p<0.01)$. The concentrations of $\mathrm{PGE}_{2}$ in IL-1 $\beta$-treated culture samples were statistically significantly different for WT and ORPK $(p<0.0001)$. In a similar fashion, IL-1 $\beta$ treatment elicited a large (12.1-fold) and statistically significant $(p<0.0001$, unpaired Student's $t$ test, $n=7$ preparations) increase in nitrite concentration in the media. By contrast, this response was completely lost in ORPK cells where there was no statistically significant difference in nitrite concentration with and without IL-1 $\beta$ (Fig. 5d). Identical experiments using bovine primary chondrocytes indicate that inhibition of PKA by PKI, at a concentration that inhibited IL-1-induced cilia elongation, also statistically significantly attenuated IL-1-induced elevations in $\mathrm{PGE}_{2}$ and nitrite (Fig. 5e, f).

\section{Discussion}

In this study, we present the effect of IL-1 on primary cilia length and highlight, for the first time, the potentially fundamental role of IFT-mediated primary cilia elongation in the progression of inflammation. Further to this, we show that some of the molecular mechanisms highlighted in previous studies apply to this cytokine-induced lengthening. Most interestingly of all, we demonstrate the key role for the cilium and IFT in downstream inflammatory signaling.

By their quiescent nature, freshly isolated primary chondrocytes represent an excellent and highly relevant non-proliferative primary cell model for studying ciliogenesis in the context of inflammation. Freshly isolated chondrocytes expressed primary cilia with a mean length of $\sim 2 \mu \mathrm{m}$ in monolayer cultures, (Fig. 1a). For comparison, in healthy bovine patellae cartilage, mean lengths of $1.1-1.5 \mu \mathrm{M}$, are observed in the superficial to deep zones, respectively [26]. In situ measurements of cilia length within cartilage tissue are difficult given the three dimensional orientation of the cilia and the resolution of confocal microscopy in the $z$ axis. By contrast, the use of isolated chondrocytes cultured in monolayer provides a simple, accurate, and reproducible measurement of primary cilia length.

Our results indicate that the pro-inflammatory cytokine, interleukin-1, stimulates cilia elongation. It is most likely that IL-1 is having an effect on pre-existing cilia rather than holding cells in G0 for longer. Cilia length has been shown to be regulated by a host of genes, proteins, and 

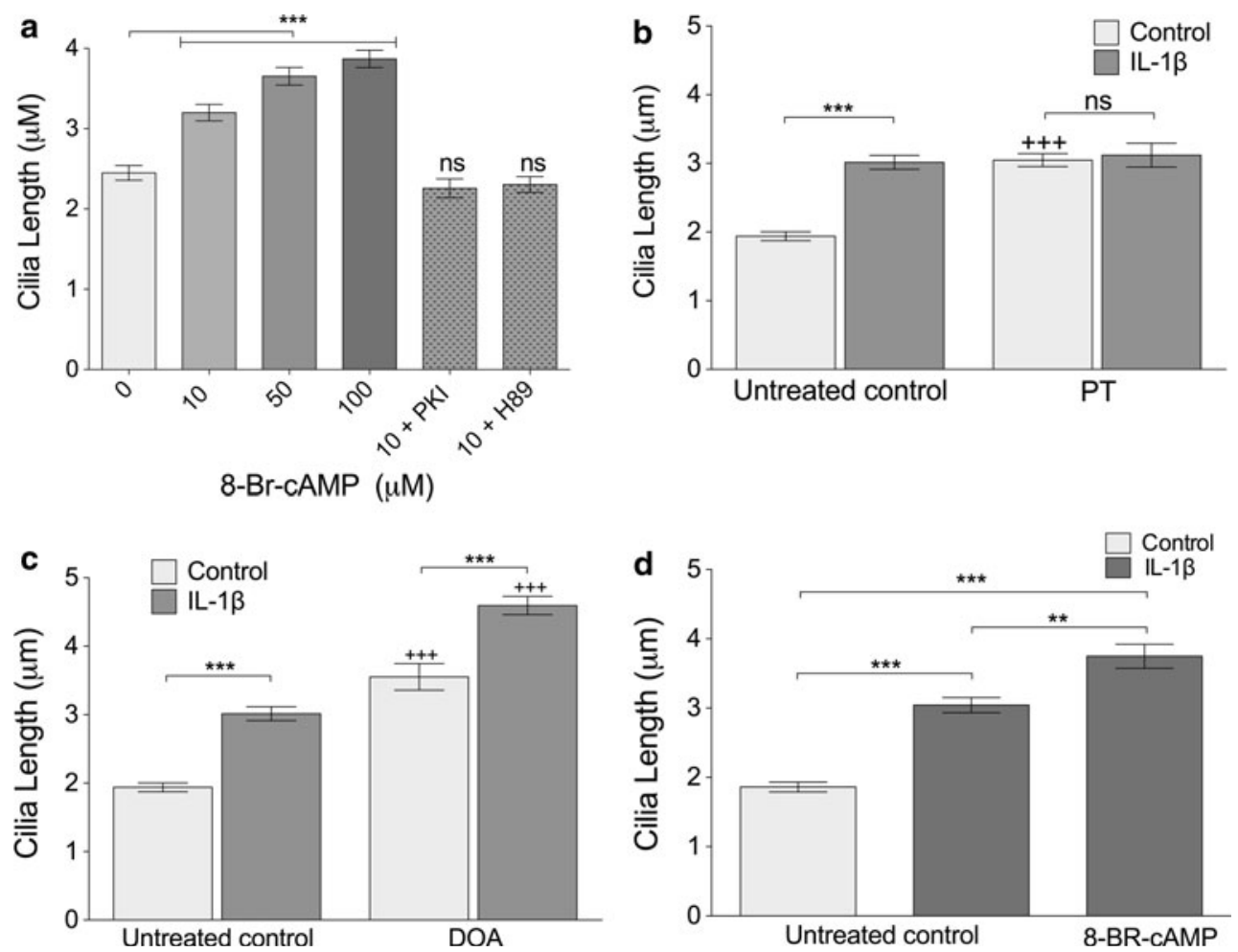

Fig. 4 The influence of G $\alpha$ i, adenylate cyclase and cAMP on cilia length appears distinct from that of IL-1. a 8-BR-cAMP treatment increased primary cilia length compared with untreated controls. The effect of 8-BR-cAMP was abolished by PKA antagonists PKI and H89 such that there were no significant differences with the untreated controls. b G-protein inhibition with pertussis toxin (PT) increased

cilia length in the absence of IL- $1 \beta(+++p<0.0001)$. There was no significant difference between IL- $1 \beta$ - and PT-treated and IL- 1 alone. c Adenylate cyclase inhibitor $2^{\prime}-5^{\prime}$ deoxyadenosine (DOA) increased cilia length in both control and IL-1-treated samples relative to corresponding controls $(+++p<0.0001)$. d IL-1 and 8-BR-cAMP combined further increased cilia length beyond that of IL-1 $\beta$ alone

signaling cascades $[13-15,22,23,35-40]$, but never by exposure to inflammatory cytokine. Cilia elongation occurred after just $3 \mathrm{~h}$ of IL-1 exposure and at the lowest concentration tested $\left(2\right.$ ng.mL $\left.{ }^{-1}\right)$. Both IL-1 $\beta$ and the cellassociated form IL- $1 \alpha$ stimulate elongation. In other tissues, fibroblasts are thought to be intermediaries in the immune reaction during an inflammatory progression that includes chemokine signaling via prostaglandins and nitric oxide release [41]. We show that this phenomenon of cilia elongation, in response to the inflammatory cytokine IL-1, is not just active in chondrocytes but is also present in fibroblasts and therefore may have implications for all inflamed tissues.

Previous pharmacological work in multiple cell types $[14,15,35]$ has indicated a role for adenylate cyclasecAMP and PKA in the extension of cilia. In synovial fibroblasts, the inhibition of adenylate cyclase, by lithium, was shown to elongate cilia [35]. Moreover, in these studies, the activity of adenylate cyclase interfered with the effects of lithium on cilia length. Conversely, however, in kidney and bone cells, the activation of adenylate cyclase by forskolin resulted in cilia elongation [14]. Our results indicate firmly that PKC, MEK-ERK, and PKA are

involved in IL-1-induced length increases (Fig. 3), but the role for cAMP was not found (Fig. 4). We found that both introduction of an analogue of cAMP and inhibition of adenylate cyclase induced cilia elongation both in isolation and supplementary to the effects of IL- 1 . We found inhibition of upstream $\mathrm{G} \alpha \mathrm{i}$ subunits also elongated cilia in isolation, but these effects did not supplement those of IL-1. This may indicate a shared role of G-protein subunits in IL-1 and adenylate cyclase mechanisms. However, importantly, we see no evidence to suggest that IL-1induced elongation and cAMP-induced elongation are linked upstream of PKA (Fig. 6). The complex roles of adenylate cyclase isoforms localized to the cilium [35] and localized changes in cAMP may explain the apparent conflicts from previous studies. Adenylate cyclase isoforms are exhibited by chondrocytes [42], and we have shown that the system is active in chondrocytes where a cAMP analogue elongates the cilium in a dose-dependent manner acting through PKA, but have no evidence for a relevance of this in the context of Inflammation.

We thus hypothesize that, in response to IL-1, downstream regulation of anterograde IFT is conducted by PKA, as has been shown previously with fluid flow mediated 
Fig. 5 IFT88 mutation and PKA inhibition both reduce inflammatory chemokine response to IL-1. Murine WT primary cilia (a) (green, antiacetylated- $\alpha$-tubulin, blue DAPI nuclei). No cilia were observed in $O R P K$ cells (b). Scale bars $10 \mu \mathrm{m}$. c $48 \mathrm{~h} \mathrm{IL-1} \beta$ exposure increased $\mathrm{PGE}_{2}$ markedly in WT cells but to a lesser extent in ORPK cells. $\mathbf{d}$ IL- $1 \beta$ treatment produced a significant increase in nitrite release in WT cells but had no effect on ORPK cells. e, f IL- $1 \beta$ treatment produced significant increases in $\mathrm{PGE}_{2}$ and nitrite in bovine chondrocytes, both of which were inhibited by treatment with PKA inhibitor PKI. Data shown are mean \pm SEM, $n=7$ preparations a
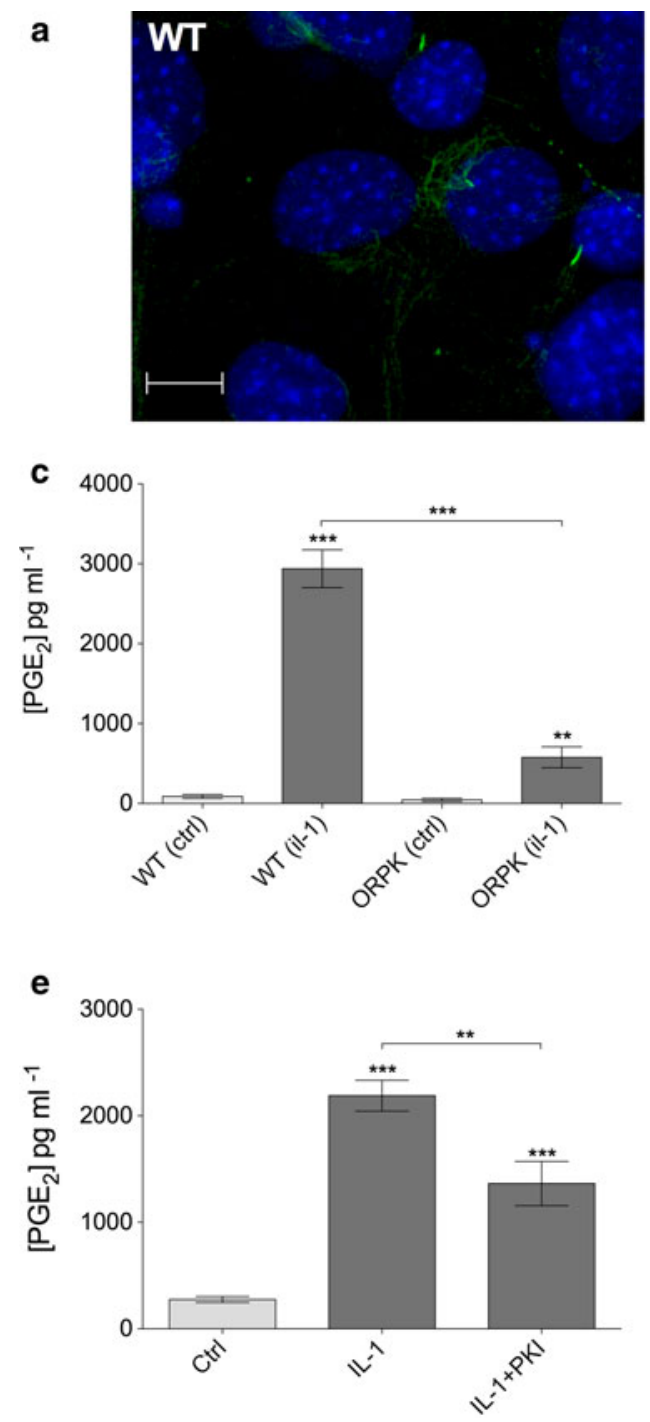

b
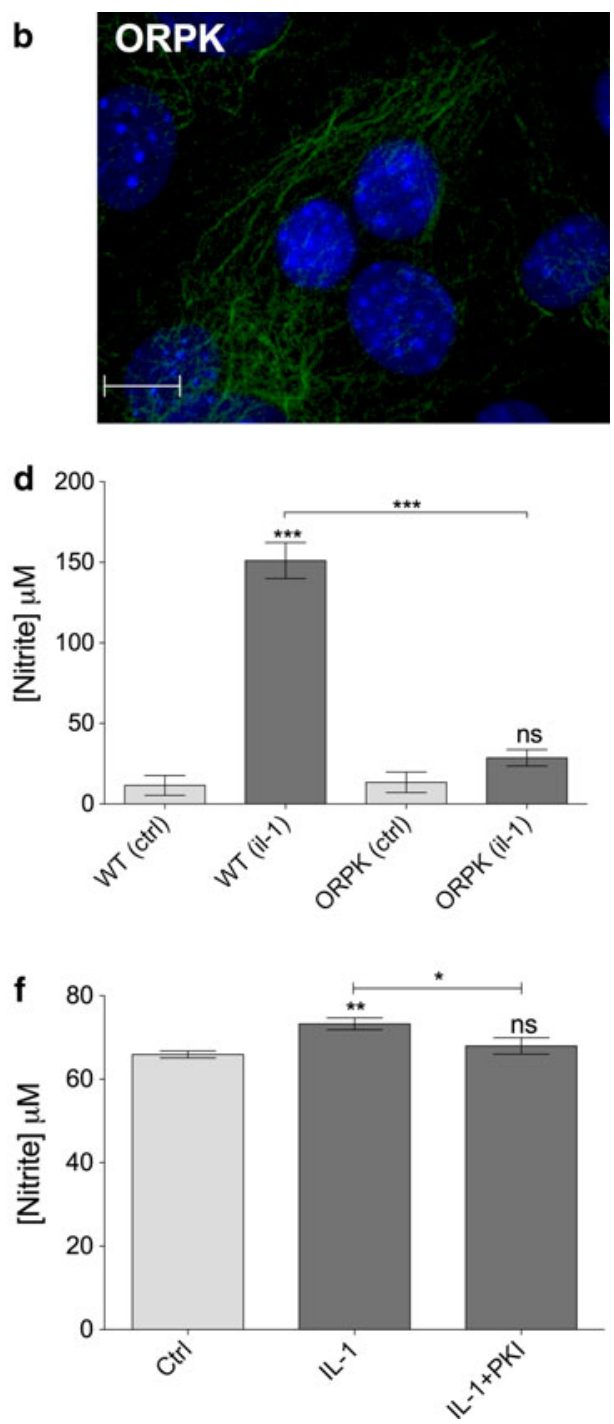

changes in cilia length [14]. Indeed, the cilia role of PKA is well established, as PKA has been linked to ciliadependent signaling systems including hedgehog and polycystin signaling [43-46]. In addition to the role of PKA, we have established that PKC and the MEK-ERK kinases are both involved in IL-1-stimulated elongation, perhaps a further indication of the complexity of IL-1elicited cellular responses. Other potential candidates involved in IFT and IL-1-induced cilia elongation include hypoxia inducible factor (HIF), [28, 47, 48], cytosolic calcium, and the actin cytoskeleton [14, 22, 23], all of which are influenced by interleukins [49]. However, this is not to exclude additional reported mechanisms including FGF signaling [50], the Dcdc2 protein [13], and the tubulin cytoskeleton itself [23]. We believe that the significance of IL-1 regulation of ciliary length may lie with hedgehog signaling alterations as supported by the correlation between structural changes, including length, and hedgehog signal transduction [36].
To investigate the role of IFT and primary cilia in downstream inflammatory signaling, the present study utilized an IFT88 mutant chondrocyte model. The $\operatorname{Tg} 737^{\text {ORPK }}$ model knocks out the IFT88 gene, disrupting polaris expression, and rendering cells with stunted [10] or, in the case of chondrocytes here, no obvious cilia structure (Fig. 5b). In response to IL-1, many cells including chondrocytes exhibit induction of nitric oxide synthase (iNOS) and cyclooxygenase 2 (COX-2) expression triggering the release of the potent inflammatory chemokines, nitric oxide (NO) and prostaglandin $\left(\mathrm{PGE}_{2}\right)$. Here, we show that loss of primary cilia and IFT88 had no effect on basal NO and $\mathrm{PGE}_{2}$, but significantly attenuated the normal up-regulation observed in WT cells in response to IL-1 $\beta$ (Fig. 5). This may explain why mechanical loading, which is known to reduce cilia length in chondrocyte [30], also down-regulates the IL- $1 \beta$-induced release of $\mathrm{NO}$ and $\mathrm{PGE}_{2}[30,51]$. It is also likely that $\mathrm{IL}-1 \beta$-induced cilia elongation will influence other aspects of cilia function including 


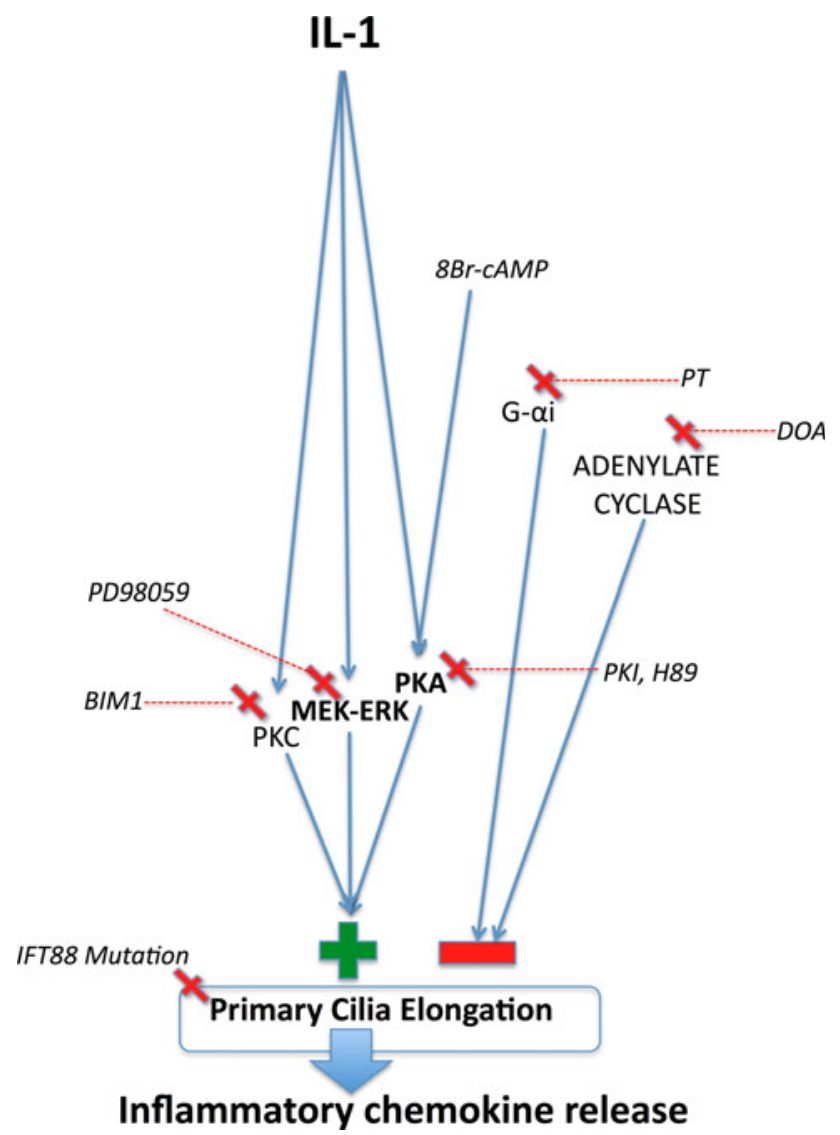

Fig. 6 Schematic summary of the proposed pathways behind IL-1 influence on chemokine release via ciliary elongation, as indicated by pharmacological and genetic experiments. IL-1 exerts positive influence on cilia elongation via PKA, MEK-ERK, and PKC. cAMP also exerts positive influence through PKA. The adenylate cyclase system exerts negative influence by separate means. There is no evidence that cAMP or adenylate cyclase are involved in IL-1induced ciliary elongation. IL-1-stimulated ciliary elongation via PKA is important to inflammatory signaling

mechanotransduction $[9,14,15]$ and hedgehog signaling which has already been linked to arthritis [27]. We finally examined the link between IL-1-induced cilia elongation via PKA (Fig. 3a) and the role of IFT88 (Fig. 5c, d) in the inflammatory response (Fig. 5e, f). We show that selective inhibition of PKA also inhibits $\mathrm{PGE}_{2}$ and $\mathrm{NO}$ release in bovine chondrocytes treated with IL-1. Thus, the cilium and associated elongation in response to IL-1 play critical roles in the activation of inflammatory chemokine signaling. The primary cilium already has central roles throughout cell biology, but here we propose, for the first time, that the cilium and the regulation of its structure and function are of fundamental importance in inflammation. The localized and specific nature of the cilia proteome governing maintenance and function of the primary cilia provides exciting potential therapeutic targets for inflammatory conditions.
Acknowledgments The authors wish to thank Courtney Haycraft and Sue McGlashan for the establishment of the ORPK cell model and A. Ofosu-Adjei and Clare Thompson for support in cilia measurement studies. Angus Wann was supported by the Wellcome Trust, UK, and Arthritis Research UK.

Open Access This article is distributed under the terms of the Creative Commons Attribution License which permits any use, distribution, and reproduction in any medium, provided the original author(s) and the source are credited.

\section{References}

1. Goetz SC, Anderson KV (2010) The primary cilium: a signalling centre during vertebrate development. Nat Rev Genet 11(5):331344

2. Tummala P, Arnsdorf EJ, Jacobs CR (2010) The role of primary cilia in mesenchymal stem cell differentiation: a pivotal switch in guiding lineage commitment. Cell Mol Bioeng 3(3):207-212

3. Kim S, Zaghloul NA, Bubenshchikova E, Oh EC, Rankin S, Katsanis N, Obara T, Tsiokas L (2011) Nde1-mediated inhibition of ciliogenesis affects cell cycle re-entry. Nat Cell Biol 13(4): 351-360

4. Michaud EJ, Yoder BK (2006) The primary cilium in cell signaling and cancer. Cancer Res 66(13):6463-6467

5. Schneider L, Cammer M, Lehman J, Nielsen SK, Guerra CF, Veland IR, Stock C, Hoffmann EK, Yoder BK, Schwab A, Satir P, Christensen ST (2010) Directional cell migration and chemotaxis in wound healing response to PDGF-AA are coordinated by the primary cilium in fibroblasts. Cell Physiol Biochem 25(2-3): 279-292

6. Malone AM, Anderson CT, Tummala P, Kwon RY, Johnston TR, Stearns T, Jacobs CR (2007) Primary cilia mediate mechanosensing in bone cells by a calcium-independent mechanism. Proc Natl Acad Sci USA 104(33):13325-13330

7. Hovater MB, Olteanu D, Hanson EL, Cheng NL, Siroky B, Fintha A, Komlosi P, Liu W, Satlin LM, Bell PD, Yoder BK, Schwiebert EM (2008) Loss of apical monocilia on collecting duct principal cells impairs ATP secretion across the apical cell surface and ATP-dependent and flow-induced calcium signals. Purinergic Signal 4(2):155-170

8. Nauli SM, Kawanabe Y, Kaminski JJ, Pearce WJ, Ingber DE, Zhou J (2008) Endothelial cilia are fluid shear sensors that regulate calcium signaling and nitric oxide production through polycystin-1. Circulation 117(9):1161-1171

9. Wann AK, Zuo N, Haycraft CJ, Jensen CG, Poole CA, McGlashan SR, Knight MM (2012) Primary cilia mediate mechanotransduction through control of ATP-induced $\mathrm{Ca}^{2+}$ signaling in compressed chondrocytes. FASEB J 26:1663-1671

10. Pazour GJ, Dickert BL, Vucica Y, Seeley ES, Rosenbaum JL, Witman GB, Cole DG (2000) Chlamydomonas IFT88 and its mouse homologue, polycystic kidney disease gene $\operatorname{tg} 737$, are required for assembly of cilia and flagella. J Cell Biol 151(3): 709-718

11. Lancaster MA, Gleeson JG (2009) The primary cilium as a cellular signaling center: lessons from disease. Curr Opin Genet Dev 19(3):220-229

12. Mokrzan EM, Lewis JS, Mykytyn K (2007) Differences in renal tubule primary cilia length in a mouse model of Bardet-Biedl syndrome. Nephron Exp Nephrol 106(3):e88-e96

13. Massinen S, Hokkanen ME, Matsson H, Tammimies K, TapiaPaez I, Dahlstrom-Heuser V, Kuja-Panula J, Burghoorn J, Jeppsson KE, Swoboda P, Peyrard-Janvid M, Toftgard R, Castren 
E, Kere J (2011) Increased expression of the dyslexia candidate gene DCDC2 affects length and signaling of primary cilia in neurons. PLoS ONE 6(6):e20580

14. Besschetnova TY, Kolpakova-Hart E, Guan Y, Zhou J, Olsen BR, Shah JV (2010) Identification of signaling pathways regulating primary cilium length and flow-mediated adaptation. Curr Biol 20(2):182-187

15. Abdul-Majeed S, Moloney BC, Nauli SM (2011) Mechanisms regulating cilia growth and cilia function in endothelial cells. Cell Mol Life Sci 69(1):165-173

16. Rosenbaum JL, Moulder JE, Ringo DL (1969) Flagellar elongation and shortening in Chlamydomonas. The use of cycloheximide and colchicine to study the synthesis and assembly of flagellar proteins. J Cell Biol 41(2):600-619

17. Asleson CM, Lefebvre PA (1998) Genetic analysis of flagellar length control in Chlamydomonas reinhardtii: a new long-flagella locus and extragenic suppressor mutations. Genetics 148(2): 693-702

18. Engel BD, Ludington WB, Marshall WF (2009) Intraflagellar transport particle size scales inversely with flagellar length: revisiting the balance-point length control model. J Cell Biol 187(1):81-89

19. Mukhopadhyay S, Lu Y, Shaham S, Sengupta P (2008) Sensory signaling-dependent remodeling of olfactory cilia architecture in C. elegans. Dev Cell 14(5):762-774

20. Lefebvre PA, Nordstrom SA, Moulder JE, Rosenbaum JL (1978) Flagellar elongation and shortening in Chlamydomonas. IV. Effects of flagellar detachment, regeneration, and resorption on the induction of flagellar protein synthesis. J Cell Biol 78(1):8-27

21. Cao M, Li G, Pan J (2009) Regulation of cilia assembly, disassembly, and length by protein phosphorylation. Methods Cell Biol 94:333-346

22. Kim J, Lee JE, Heynen-Genel S, Suyama E, Ono K, Lee K, Ideker T, Aza-Blanc P, Gleeson JG (2010) Functional genomic screen for modulators of ciliogenesis and cilium length. Nature 464(7291):1048-1051

23. Sharma N, Kosan ZA, Stallworth JE, Berbari NF, Yoder BK (2011) Soluble levels of cytosolic tubulin regulate ciliary length control. Mol Biol Cell 22(6):806-816

24. Deane JA, Ricardo SD (2012) Emerging roles for renal primary cilia in epithelial repair. Int Rev Cell Mol Biol 293:169-193

25. Jensen CG, Poole CA, McGlashan SR, Marko M, Issa ZI, Vujcich KV, Bowser SS (2004) Ultrastructural, tomographic and confocal imaging of the chondrocyte primary cilium in situ. Cell Biol Int 28(2):101-110

26. McGlashan SR, Cluett EC, Jensen CG, Poole CA (2008) Primary cilia in osteoarthritic chondrocytes: from chondrons to clusters. Dev Dyn 237(8):2013-2020

27. Lin AC, Seeto BL, Bartoszko JM, Khoury MA, Whetstone H, Ho L, Hsu C, Ali SA, Alman BA (2009) Modulating hedgehog signaling can attenuate the severity of osteoarthritis. Nat Med 15(12): 1421-1425

28. Verghese E, Zhuang J, Saiti D, Ricardo SD, Deane JA (2011) In vitro investigation of renal epithelial injury suggests that primary cilium length is regulated by hypoxia-inducible mechanisms. Cell Biol Int 35(9):909-913

29. Dinarello CA (2011) A clinical perspective of IL-1beta as the gatekeeper of inflammation. Eur J Immunol 41(5):1203-1217

30. Chowdhury TT, Bader DL, Lee DA (2001) Dynamic compression inhibits the synthesis of nitric oxide and PGE(2) by IL-1betastimulated chondrocytes cultured in agarose constructs. Biochem Biophys Res Commun 285(5):1168-1174

31. Yoder BK, Richards WG, Sommardahl C, Sweeney WE, Michaud EJ, Wilkinson JE, Avner ED, Woychik RP (1997) Differential rescue of the renal and hepatic disease in an autosomal recessive polycystic kidney disease mouse mutant. A new model to study the liver lesion. Am J Pathol 150(6): 2231-2241

32. McGlashan SR, Jensen CG, Poole CA (2006) Localization of extracellular matrix receptors on the chondrocyte primary cilium. J Histochem Cytochem 54(9):1005-1014

33. Lee DA, Frean SP, Lees P, Bader DL (1998) Dynamic mechanical compression influences nitric oxide production by articular chondrocytes seeded in agarose. Biochem Biophys Res Commun 251(2):580-585

34. Kwon RY, Temiyasathit S, Tummala P, Quah CC, Jacobs CR (2010) Primary cilium-dependent mechanosensing is mediated by adenylyl cyclase 6 and cyclic AMP in bone cells. FASEB J 24(8):2859-2868

35. Ou Y, Ruan Y, Cheng M, Moser JJ, Rattner JB, van der Hoorn FA (2009) Adenylate cyclase regulates elongation of mammalian primary cilia. Exp Cell Res 315(16):2802-2817

36. Tran PV, Haycraft CJ, Besschetnova TY, Turbe-Doan A, Stottmann RW, Herron BJ, Chesebro AL, Qiu H, Scherz PJ, Shah JV, Yoder BK, Beier DR (2008) THM1 negatively modulates mouse sonic hedgehog signal transduction and affects retrograde intraflagellar transport in cilia. Nat Genet 40(4):403-410

37. Verghese E, Ricardo SD, Weidenfeld R, Zhuang J, Hill PA, Langham RG, Deane JA (2009) Renal primary cilia lengthen after acute tubular necrosis. J Am Soc Nephrol 20(10):2147-2153

38. McGlashan SR, Knight MM, Chowdhury TT, Joshi P, Jensen CG, Kennedy S, Poole CA (2010) Mechanical loading modulates chondrocyte primary cilia incidence and length. Cell Biol Int 34(5):441-446

39. Gardner K, Arnoczky SP, Lavagnino M (2011) Effect of in vitro stress-deprivation and cyclic loading on the length of tendon cell cilia in situ. J Orthop Res 29(4):582-587

40. Palmer KJ, MacCarthy-Morrogh L, Smyllie N, Stephens DJ (2011) A role for Tctex-1 (DYNLT1) in controlling primary cilium length. Eur J Cell Biol 90(10):865-871

41. Espanol AJ, Goren N, Ribeiro ML, Sales ME (2010) Nitric oxide synthase 1 and cyclooxygenase- 2 enzymes are targets of muscarinic activation in normal and inflamed NIH3T3 cells. Inflamm Res 59(3):227-238

42. Memon I, Khan KM, Siddiqui S, Perveen S, Ishaq M (2010) Temporal expression of calcium/calmodulin-dependent adenylyl cyclase isoforms in rat articular chondrocytes: RT-PCR and immunohistochemical localization. J Anat 217(5):574-587

43. Tukachinsky H, Lopez LV, Salic A (2010) A mechanism for vertebrate Hedgehog signaling: recruitment to cilia and dissociation of SuFu-Gli protein complexes. J Cell Biol 191(2):415-428

44. Chen Y, Yue S, Xie L, Pu XH, Jin T, Cheng SY (2011) Dual Phosphorylation of suppressor of fused (Sufu) by PKA and GSK3beta regulates its stability and localization in the primary cilium. J Biol Chem 286(15):13502-13511

45. Choi YH, Suzuki A, Hajarnis S, Ma Z, Chapin HC, Caplan MJ, Pontoglio M, Somlo S, Igarashi P (2011) Polycystin-2 and phosphodiesterase 4C are components of a ciliary A-kinase anchoring protein complex that is disrupted in cystic kidney diseases. Proc Natl Acad Sci USA 108(26):10679-10684

46. Barzi M, Berenguer J, Menendez A, Alvarez-Rodriguez R, Pons S (2010) Sonic-hedgehog-mediated proliferation requires the localization of PKA to the cilium base. J Cell Sci 123(Pt 1):62-69

47. Toffoli S, Feron O, Raes M, Michiels C (2007) Intermittent hypoxia changes HIF-1alpha phosphorylation pattern in endothelial cells: unravelling of a new PKA-dependent regulation of HIF-1alpha. Biochim Biophys Acta 1773(10):1558-1571

48. Qian D, Lin HY, Wang HM, Zhang X, Liu DL, Li QL, Zhu C (2004) Normoxic induction of the hypoxic-inducible factor-1 alpha by interleukin-1 beta involves the extracellular signal-regulated kinase $1 / 2$ pathway in normal human cytotrophoblast cells. Biol Reprod 70(6):1822-1827 
49. Pritchard S, Guilak F (2006) Effects of interleukin-1 on calcium signaling and the increase of filamentous actin in isolated and in situ articular chondrocytes. Arthritis Rheum 54(7):2164-2174

50. Neugebauer JM, Amack JD, Peterson AG, Bisgrove BW, Yost HJ (2009) FGF signalling during embryo development regulates cilia length in diverse epithelia. Nature 458(7238):651-654
51. Agarwal S, Long P, Gassner R, Piesco NP, Buckley MJ (2001) Cyclic tensile strain suppresses catabolic effects of interleukin1 beta in fibrochondrocytes from the temporomandibular joint. Arthritis Rheum 44(3):608-617 